\title{
IMPROUEMENT OF STUDENT PHYSICAL STATE AND COORDINATION OF MOVEMENTS BY MEANS OF ALISH BELT WRESTLING
}

\author{
Olexandr Voloshin, 1, A, B, D, E Olexandr Kolenkov², B, C, E \\ ${ }^{1}$ National Pedagogical Dragomanov University, Ukraine \\ ${ }^{2}$ Azov State Technical University, Mariupol, Ukraine \\ A Study Design; ${ }^{\mathrm{B}}$ Data Collection; ${ }^{\mathrm{C}}$ Statistical Analysis; ${ }^{\mathrm{D}}$ Manuscript Preparation; ${ }^{\mathrm{E}}$ Funds Collection \\ Address for correspondence: \\ Oleksandr Voloshin \\ Faculty of Physical Education, Sport and Health, National Pedagogical Dragomanov University \\ Turgenevskaya street 3-9, 01054, Kiev, Ukraine \\ E-mail: VoloshynAleksander@gmail.com
}

\begin{abstract}
Ahstract The paper presents data on the improvement of motion coordination in students by means of Alish belt wrestling in the process of physical education and its impact on physical development level. The program of student physical development and physical fitness enhancement by means of motion coordination improvement in the process of taking belt wrestling course and further ways of students' development has been elaborated. The problem's importance and the necessity of further elaborating the methods of student preparation by means of belt wrestling have been substantiated. The problems associated with elaboration of scientifically substantiated system of belt wrestlers' preparation that will permit to increase the reserve capacities of student motor system and improve the quality of motion control have been set up.
\end{abstract}

Key worlls Alish, belt wrestling, students, coordination, motions

\section{Introduction}

Formation of student motion coordination by means of Alish belt wrestling, that is training of technical actions, is associated with further development of scientifically substantiated system of improving specialized physical fitness, physical development, thus enabling to increase the reserve capacities and the quality of motion control in the process of physical education at higher education institution.

Motor training of students in the process of Alish belt wrestling is aimed at the development of strength, speed, coordination capacities, flexibility and endurance. Depending on exercise direction and the character of their performance, the methods of physical capacity development at the Alish belt wrestling sessions include: repeated serial, continuous and interval, circular, gaming and competitive method. 
Means of motor training in the process of Alish belt wrestling sessions are general developing, preparatory and competitive exercises of different coordination structure, the performance of which, at different stages of annual education and training process, contributes to increase of the motor system reserve capabilities.

Despite the fact that the formation of student motion coordination by means of Alish belt wrestling is an important condition for sports training of wrestlers, there are still insufficient scientific data about the reserve capabilities of the motor system of belt wrestlers (Arziutov, Hrishchenko, Chizhaiev, 2009). The issues of different physical education methods impact on both the interrelation of movements of different coordination structures with the level of technical fitness of students-athletes and the reserve capabilities of the motion control system in the process of sports training of students are inadequately treated (Pryimakov, Dotsenko, Prysiazhniuk, 2014; Blume, 1983, 1984; Jascaninas, Monogarov, 1987).

The solution of set problem is associated with the development of a scientifically substantiated system of belt wrestlers' preparation. However, it has not been given sufficient attention, although it is extremely complex and important for improving the physical education of students and enhancing their sports achievements (Pryimakov, Dotsenko, 2006; Samokish, Bosenko, Pryimakov, Biletskaya, 2017).

The modern theoretical basis and practical experience of leading national and foreign researchers have been used as a theoretico-methodical foundation for elaboration of the content of student motor training in the process of Alish belt wrestling sessions: V.G. Arefyeva (2010), H.M. Arziutova, V.N. Hrishenkova, P. Chizhaieva (2009), T.I. Krutsevych (2012), O.O. Pryimakov, O.O. Dovgich (2003).

\section{Material and Methods}

Well known tests checked for authenticity and described in various textbooks and methodical recommendations as well as compared with State tests and norms were used to study the motor fitness of students (Apanasenko, 2004; Samokish, 2018; Seluyanov, Dimova, 2002; State program of physical culture and sport development in Ukraine, 1994).

Numerous experts (Hirtz, Vilkner, 1985; Mekota, Blahus, 1983; Schnabel, 1994; Sergienko, 2001) believe that the question of criteria for evaluating physical state of athletes, creation of authentic methods and elaboration of the tests is the most significant in the problem of 'coordination technique'.

Study protocol was approved by University Ethics Committee. The research was fulfilled in compliance with WMA Declaration of Helsinki - Ethical Principles for Medical Research Involving Human Subjects (2013).

General motor fitness of athletes was assessed by means of control exercises, which provided information about the level of manifesting the major human physical capacities (endurance, strength and speed-strength capacities, speed, agility and flexibility) and were envisaged by the requirements of the educational program in physical education of students.

The level of endurance manifestation was determined by the results of $3,000 \mathrm{~m}$ run; that of strength according to the number of pull-ups and push-ups, that of speed - according to the time of covering $100 \mathrm{~m}$ distance; that of agility - by the results of $4 \times 9 \mathrm{~m}$ shuttle run; that of flexibility - by the results of trunk forward bending in sitting position $(\mathrm{cm})$, and that of speed-strength capacities - according to the result of standing long jump (cm).

Proceeding from the above, a comparative analysis of the physical fitness and physiometric indices of experimental group students (EG - 34 persons), whose movements of different coordination structures were 
developed by means of Alish belt wrestling and the control group of students (CG - 30 persons) that were engaged in the traditional physical education program and attended elective classes by choice, was conducted.

Initial values of physical development indices (body length and mass, height-mass index, Quetelet index), those of cardiovascular system functional state (HR, systolic BP, diastolic BP, circulation efficiency), indices of external respiration system (VC, MPV, timed inspiratory capacity, timed expiratory capacity), those of physical development and endurance (3,000 m run), speed data (100 m run), agility data ( $4 \times 9 \mathrm{~m}$ shuttle run), speed-strength indices (standing long jump), strength indices (strength of right and left hand, strength index, pull-ups, right/left leg squats), data of functional tests (Martine-Kushelevsky's test, Harvard step-test index, Kerdo index), agility and other data of complex examining both groups of students were presented. The studies were conducted before and at the end of the experiment (after three years of training according to special methods for motion coordination formation by means of Alish belt wrestling). The presented results are a starting point for evaluation of the students' physical preparation structure and comparing those results with literary data in order to establish the influence of physical education means on morphofunctional development and manifestation of movements of different coordination structure in the dynamics of pedagogical experiment (Novytskyi, 2010; Seluyanov, Dimova, 2002; Sergienko, 2001).

STATISTICA 13.3 (StatSoft) software was used for statistical processing of experimental material.

\section{Results}

Anthropometric, physiometric and strength indices of both student groups were similar before the experiment: the difference in body mass, Quetelet index, height-mass index, VC, vital and strength indices differed by no more than $8.5 \%(p>0.05)$. However, after the implementation of the program of special physical education by means of Alish belt wrestling, the data at the end of the experiment showed significant differences.

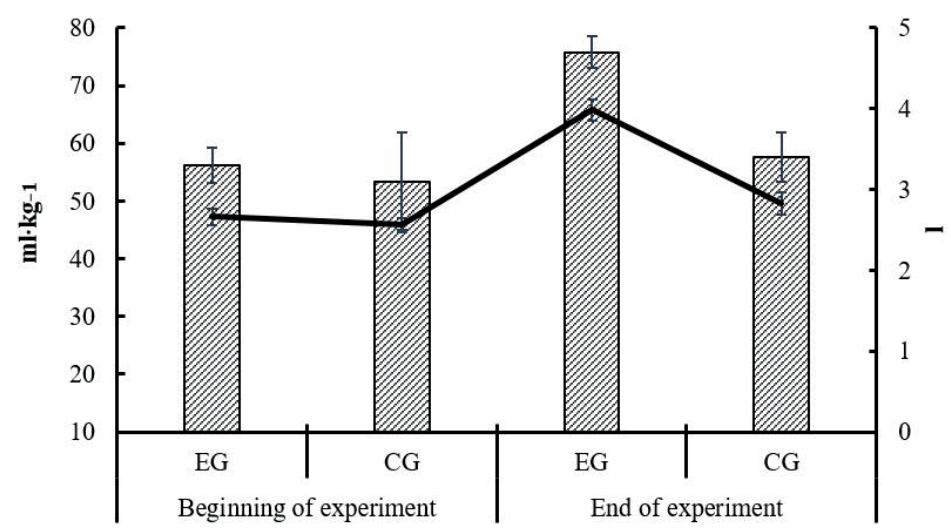

एवL, 1 Vital index, $\mathrm{ml} \cdot \mathrm{kg}^{-1}$

Figure 1. VC and vital index at the beginning and at the end of the experiment. EG - experimental group; CG - control group 
The main changes that characterized the improvement of the EG students' physical state were: an increase of the vital index (by $34.3 \%$ at $p \leq 0.05$ ) and VC (by 42.4\%, $p<0.05$ ) (Figure 1), the strength of right and left hand (respectively $33.5 \%, p \leq 0.05$ and $30.2 \%, p \leq 0.05$ ). This resulted in an increase of the strength index (by $30.5 \%$, $p<0.05)$. At the same time, indices of CG students changed insignificantly $(p>0.05)$.

The analysis of individual aspects of functional fitness and physical work capacity of both student groups before and after pedagogical experiment demonstrated that the most significant changes of functional state occurred in students of the EG in: indices of arterial blood pressure, HR during the recovery period after testing physical loads, Harvard step-test, Martine-Kushelevsky's test and data of circulation efficiency.

Changes in the indices of cardiovascular system functional state indicate that the regular engagement in single combats tends to improve the student's physical state significantly (Table 1).

Table 1. Indices of cardiovascular system functional state and physical work capacity of students in pedagogical experiment

\begin{tabular}{|c|c|c|c|c|}
\hline Index & $\begin{array}{c}\text { Groups: } \\
\text { EG }(n=34) \\
\text { CG }(n=30)\end{array}$ & $\begin{array}{l}\text { Beginning of experiment } \\
\qquad M \pm m\end{array}$ & $\begin{array}{l}\text { End of experiment } \\
\qquad M \pm m\end{array}$ & $p$ \\
\hline \multirow{2}{*}{ Pulse, bt/min., (HR) } & EG & $76.2 \pm 1.52$ & $71.4 \pm 1.39$ & $<0.050$ \\
\hline & CG & $77.4 \pm 1.28$ & $73.5 \pm 1.64$ & $>0.050$ \\
\hline \multirow{2}{*}{ Systolic BP, mm. Hg. } & EG & $112.5 \pm 1.45$ & $110.1 \pm 1.58$ & $>0.020$ \\
\hline & CG & $120.7 \pm 1.28$ & $118.8 \pm 2.10$ & $>0.020$ \\
\hline \multirow{2}{*}{ Diastolic BP, mm. Hg. } & EG & $72.8 \pm 1.02$ & $70.1 \pm 1.10$ & $>0.050$ \\
\hline & CG & $73.1 \pm 1.41$ & $72.3 \pm 1.81$ & $>0.050$ \\
\hline \multirow{2}{*}{ Circulation efficiency coefficient, un } & EG & $3,025.1 \pm 112.7$ & $2,856.0 \pm 127.1$ & $<0.050$ \\
\hline & CG & $3,684.2 \pm 122.5$ & $3,417.8 \pm 130.2$ & $>0.050$ \\
\hline \multirow{2}{*}{ Martine-Kushelevsky's test, min } & EG & $2.2 \pm 0.47$ & $1.4 \pm 0.27$ & $<0.005$ \\
\hline & CG & $2.3 \pm 0.51$ & $2.0 \pm 0.42$ & $>0.050$ \\
\hline \multirow{2}{*}{ Kerdo index, \% } & EG & $4.47 \pm 2.21$ & $1.82 \pm 1.17$ & $<0.005$ \\
\hline & CG & $5.56 \pm 2.84$ & $1.63 \pm 1.58$ & $<0.005$ \\
\hline \multirow{2}{*}{ Harvard step-test index, un } & EG & $80.5 \pm 2.81$ & $92.1 \pm 2.14$ & $<0.050$ \\
\hline & CG & $78.9 \pm 1.98$ & $83.8 \pm 2.52$ & $>0.050$ \\
\hline
\end{tabular}

An increase of physical work capacity level (by $14.4 \%$ at $p \leq 0.05$ ) and the reduction of recovery time after physical loads during performance of Harvard step-test were noted in EG along with the improvement of physical work capacity indices according to Martine-Kushelevsky's test (by 36.4\%) and circulation efficiency coefficient from 3,025.1 \pm 112.7 un. to 2,856.0 \pm 127.1 un. The decrease of the given coefficient indices indicates the processes of reduced fatigue under high physical loads. The difference in circulation efficiency coefficient indices at the end of the experiment was $19.6 \%$ higher in the experimental group as compared to the control one.

The analysis of experimental material demonstrated a significant decrease of pulse in students of EG during the recovery period after testing loads, as well as less expressed response to physical loads and faster HR decrease during the recovery period as compared to data of CG students and those before pedagogical experiment. This is indicative of enhanced reserve functional capacities of the body of EG students. 
Only in CG the tendency for physical work capacity increase (by $6.2 \%$ at $>0.05$ ) and the decrease of HR recovery time after physical load during Harvard step-test execution $(p>0.05)$ was observed.

The difference in the Kerdo index between subjects of EG and CG is negligible, although it is evident that the excitation processes in both groups exceed those of inhibition in the activity of the autonomic nervous system. However, at the end of the pedagogical experiment there was a clear approximation of the data to the functional equilibrium $(p<0.005)$ in both groups.

The results of assessing general physical fitness of students according to control standards demonstrated positive changes in the development of motor qualities in both groups (Table 2).

At the end of the experiment the following indices increased significantly in students of EG: endurance $(20.3 \%$ increment, $p \leq 0.05)$, speed (12.9\% increment, $p \leq 0.05)$, agility (21.8\% increment, $p \leq 0.05)$, arm strength ( $47.7 \%$ increment, $p \leq 0.05$ ), speed-strength capacities (12.7\% increment, $p \leq 0.05)$ and leg strength $(44.3 \%$ and $40.6 \%$ increase of the number of right and left leg squats, respectively, $p<0.05$ ). In CG the following increments were noted: endurance $-3.2 \%$, speed $-8.2 \%$, agility $-6.9 \%$, arm strength $-4.8 \%$, speed-strength capacities $-2.5 \%$ and right and left leg strength $8.5 \%$ and $9.2 \%$, respectively. These changes, however, were statistically insignificant $(p>0.05)$.

Slightly lower results were observed in endurance motor tests (3,000 m running), speed (100 m running), speed-strength capacities (standing long jump) and agility ( $4 \times 9 \mathrm{~m}$ shuttle run), whereas much better indices were noted in strength tests (pull-ups and right and left leg squats) (Table 2).

Table 2. Physical fitness indices of students in pedagogical experiment

\begin{tabular}{|c|c|c|c|c|}
\hline Types of testing & $\begin{array}{c}\text { Groups: } \\
\text { EG }(n=34), \\
\text { CG }(n=30)\end{array}$ & $\begin{array}{l}\text { Beginning of experiment } \\
\qquad M \pm m\end{array}$ & $\begin{array}{l}\text { End of experiment } \\
\qquad \mathrm{M} \pm \mathrm{m}\end{array}$ & $p$ \\
\hline \multirow{2}{*}{3,000 m running, $\min , s$} & $E G$ & $16.0 \pm 1.3$ & $13.3 \pm 1.8$ & $\leq 0.05$ \\
\hline & CG & $16.1 \pm 1.8$ & $15.6 \pm 1.3$ & $>0.05$ \\
\hline \multirow{2}{*}{100 m running, s } & $E G$ & $15.7 \pm 0.8$ & $13.9 \pm 0.4$ & $\leq 0.05$ \\
\hline & CG & $15.8 \pm 0.7$ & $14.6 \pm 0.5$ & $>0.05$ \\
\hline \multirow{2}{*}{ Pull-ups, number } & $E G$ & $23.5 \pm 1.29$ & $34.7 \pm 1.74$ & $\leq 0.05$ \\
\hline & CG & $22.8 \pm 1.23$ & $23.9 \pm 1.25$ & $\leq 0.05$ \\
\hline \multirow{2}{*}{ Standing long jump, cm } & $E G$ & $212.2 \pm 2.26$ & $239.5 \pm 2.16$ & $\leq 0.05$ \\
\hline & CG & $218.3 \pm 2.21$ & $223.8 \pm 2.18$ & $>0.05$ \\
\hline \multirow{2}{*}{$4 \times 9 \mathrm{~m}$ shuttle run, $\mathrm{s}$} & $E G$ & $10.6 \pm 1.2$ & $8.7 \pm 0.5$ & $\leq 0.05$ \\
\hline & CG & $10.8 \pm 1.0$ & $10.1 \pm 1.0$ & $>0.05$ \\
\hline \multirow{2}{*}{ Right leg squats, number } & $E G$ & $11.5 \pm 1.01$ & $16.6 \pm 0.88$ & $<0.05$ \\
\hline & CG & $10.8 \pm 0.87$ & $11.5 \pm 1.12$ & $>0.05$ \\
\hline \multirow{2}{*}{ Left leg squats, number } & $E G$ & $10.6 \pm 1.35$ & $14.9 \pm 1.26$ & $<0.05$ \\
\hline & CG & $9.8 \pm 0.79$ & $10.7 \pm 1.30$ & $>0.05$ \\
\hline
\end{tabular}

The results presented in Table 3 show that the level of special motor fitness of EG students in Alish belt wrestling has increased significantly in the dynamics of pedagogical experiment (Table 3). 
Table 3. Indices of student special motor fitness under conditions of pedagogical experiment

\begin{tabular}{lcccc}
\hline \multicolumn{1}{c}{ Types of testing } & $\begin{array}{c}\text { Groups: } \mathrm{EG}(\mathrm{n}=34), \\
\mathrm{CG}(\mathrm{n}=30)\end{array}$ & $\begin{array}{c}\text { Beginning of experiment } \\
\mathrm{M} \pm \mathrm{m}\end{array}$ & $\begin{array}{c}\text { End of experiment } \\
\mathrm{M} \pm \mathrm{m}\end{array}$ & $\mathrm{p}$ \\
\hline \multirow{2}{*}{ Push-ups, number } & EG & $17.5 \pm 2.51$ & $24.4 \pm 1.84$ & $<0.05$ \\
& CG & $16.9 \pm 1.78$ & $18.6 \pm 2.21$ & $>0.05$ \\
\hline \multirow{2}{*}{ Standing high jump, cm } & EG & $42.2 \pm 1.81$ & $48.0 \pm 1.59$ & $<0.05$ \\
& CG & $40.1 \pm 2.01$ & $42.3 \pm 2.20$ & $>0.05$ \\
\hline \multirow{2}{*}{ Trunk forward bending in sitting position, $\mathrm{cm}$} & EG & $15.8 \pm 1.23$ & $19.5 \pm 2.14$ & $<0.05$ \\
& CG & $13.2 \pm 2.02$ & $14.2 \pm 1.98$ & $>0.05$ \\
\hline \multirow{2}{*}{ Sit-ups in 1 min, number } & EG & $27.6 \pm 1.03$ & $39.4 \pm 0.98$ & $<0.05$ \\
& CG & $26.5 \pm 1.14$ & $29.6 \pm 1.28$ & $>0.05$ \\
\hline
\end{tabular}

In students of the EG the following parameters increased: the dynamic strength endurance of the upper extremities - by $39.4 \%(p<0.05)$; the explosive power of legs - by $13.7 \%(p<0.05)$; spine mobility (flexibility) - by $23.4 \%$ ( $p<0.05)$, strength of abdominal muscles - by $42.8 \%(p<0.05)$. At the same time, the CG students demonstrated insignificant improvement of the indices of special motor capacity development $(p>0.05)$.

During three years of the experiment, the students enhanced their physical development and physical fitness significantly through the improvement of motion coordination by means of Alish belt wrestling, which was reflected in their motor abilities and strength data, indices of agility, speed-strength tests and spine flexibility. These differences may be explained by more qualitative rearrangements in the motor system of the students, which has been influenced by engagement in belt wrestling, and is indicative of the higher functional reserves of their motor system, including coordination abilities.

This gave impetus to the increase of technical capacities of wrestlers, which is clearly reflected in the analysis of temporal characteristics and the study of phase structures of the technique of throw execution at the beginning and at the end of the pedagogical experiment conducted in EG (Table 4).

Table 4. Results of analysis of throw execution time by belt wrestlers during pedagogical experiment

\begin{tabular}{|c|c|c|c|c|c|c|c|c|}
\hline \multirow{2}{*}{\multicolumn{2}{|c|}{$\begin{array}{l}\text { Index of throw execution time } \\
\qquad(n-34)\end{array}$}} & \multicolumn{2}{|c|}{ Beginning of experiment } & \multicolumn{2}{|c|}{ End of experiment } & \multirow{2}{*}{$\begin{array}{c}\text { Percent } \\
\text { of changes }\end{array}$} & \multirow{2}{*}{$t$} & \multirow{2}{*}{$\mathrm{p}$} \\
\hline & & $M$ & $\pm \mathrm{m}$ & $M$ & $\pm m$ & & & \\
\hline \multirow{4}{*}{$\begin{array}{l}\text { Duration of throw } \\
\text { preparation, s }\end{array}$} & Hip-roll, lateral & 1.86 & 0.1 & 1.16 & 0.25 & 60.3 & 2.60 & $<0.01$ \\
\hline & Valley drop throw & 1.87 & 0.16 & 1.19 & 0.71 & 57.1 & 0.93 & $>0.05$ \\
\hline & Lateral drop sweep & 1.89 & 0.15 & 1.2 & 0.15 & 57.5 & 3.25 & $<0.01$ \\
\hline & Two-leg pick-up & 1.93 & 0.1 & 1.22 & 0.28 & 58.2 & 2.39 & $<0.02$ \\
\hline \multirow{4}{*}{$\begin{array}{l}\text { Duration } \\
\text { of of phase } \\
\text { of throw itself, s }\end{array}$} & Hip-roll, lateral & 1.74 & 0.28 & 1.14 & 0.58 & 52.6 & 0.93 & $>0.05$ \\
\hline & Valley drop throw & 1.52 & 0.1 & 1.08 & 0.15 & 40.7 & 2.44 & $<0.02$ \\
\hline & Lateral drop sweep & 1.34 & 0.18 & 1.06 & 21 & 26.4 & 0.01 & $>0.05$ \\
\hline & Two-leg pick-up & 1.58 & 0.18 & 1.11 & 0.15 & 42.3 & 2.01 & $<0.05$ \\
\hline \multirow{4}{*}{$\begin{array}{l}\text { Duration of throw } \\
\text { phase on the } \\
\text { whole, s }\end{array}$} & Hip-roll, lateral & 3.6 & 0.18 & 2.3 & 0.47 & 56.5 & 2.58 & $<0.01$ \\
\hline & Valley drop throw & 3.39 & 0.21 & 2.27 & 0.13 & 49.3 & 4.53 & $<0.01$ \\
\hline & Lateral drop sweep & 3.23 & 0.19 & 2.26 & 0.14 & 42.9 & 4.11 & $<0.01$ \\
\hline & Two-leg pick-up & 3.51 & 0.23 & 2.33 & 0.21 & 50.6 & 3.79 & $<0.01$ \\
\hline
\end{tabular}


While comparing the duration of hold execution during pedagogical experiment, one should state that the given changes in belt wrestlers' preparation significantly improve technical parameters of throw execution at the end of the conducted experiment.

For instance, the duration of lateral hip-roll decreased from $3.60 \pm 0.18 \mathrm{~s}$ at the beginning of experiment to 2.12 $\pm 0.14 \mathrm{~s}(\mathrm{p}<0.05)$ at the end.

The reduction of the duration of action initial phases is especially noteworthy.

For instance, the duration of preparation for throw execution decreased from $1.86 \pm 0.12 \mathrm{~s}$ at the beginning of experiment to $1.12 \pm 0.16 s$ at the end ( $\leq \leq 0.05$ ). Similar data were obtained during the study of duration of performing other holds/actions by wrestlers.

In addition to the analysis of temporal characteristics and the study of the phase structures of throw execution technique, an expert evaluation method was used for more objective assessment of Alish belt wrestling efficiency.

This method is based on an expert assessment of throws on a five-point system before and after the experiment (Table 5).

Table 5. Expert estimates of performing throws of different coordination structure before and after experiment, points

\begin{tabular}{lcccccccc}
\hline \multirow{2}{*}{$\begin{array}{c}\text { Number of subjects } \\
\text { ( } \mathrm{n}-34)\end{array}$} & \multicolumn{4}{c}{ Before experiment } \\
\cline { 2 - 10 } & 1 & 2 & 3 & 4 & 1 & 2 & 3 & 4 \\
\hline $\mathrm{M}$ & 2.45 & 2.40 & 2.80 & 2.32 & 4.19 & 3.91 & 4.79 & 3.84 \\
$\pm \mathrm{m}$ & 0.27 & 0.34 & 0.29 & 0.31 & 0.37 & 0.42 & 0.44 & 0.47 \\
$\mathrm{p}$ & $<0.001$ & $<0.005$ & $<0.005$ & $<0.001$ & $<0.001$ & $<0.001$ & $<0.001$ & $<0.005$ \\
\hline
\end{tabular}

Note: 1 - lateral hip-roll; 2 - valley drop throw; 3 - lateral drop sweep; 4 - two-leg pick-up.

As shown in Table 5, the experimental methods of training resulted in an increased value of average points of throws. Increment of average value of lateral hip-roll constituted $71.3 \%$; that of valley drop throw $-65.5 \%$; that of lateral drop sweep $-71.7 \%$ and that of two-leg pick-up - 65.9\% $(p<0.001)$.

At the end of the experiment, in spite of the overall increase in the quality of throw performance, significant difficulties remained in the execution of the valley drop throw and two-leg pick-up, which had the lowest average scores and the lowest increment of the indices of performance quality. As opposed to the above-mentioned situation, at the end of the experiment, the belt wrestlers showed excellent mastery of the technique of hip-roll and lateral drop sweep, received high average scores and experienced a significant increase in the indices of the quality of the above techniques performance.

In our opinion, this training's effect was mainly due to the usage of specialized motions of various coordination structure peculiar for Alish belt wrestling, which helped to develop qualities and skills necessary for mastering the given technique by the wrestlers. Therefore, the most efficient specialized holds and actions - lateral hip-roll and lateral drop sweep - were further used to improve motion coordination of students.

\section{Discussion}

The findings demonstrate that the level of student physical fitness is determined by their motor activity mode. The most efficient in this regard are those motor modes that were developed for EG. They are mainly focused 
on the complex enhancement of the level of physical capacity development, formation and improvement of student motion coordination by using regular and extended exercises of acyclic character in the form of Alish belt wrestling in extracurricular physical culture and sports activities.

Despite numerous works dealing with the problem of student physical fitness under modern conditions of physical education organization at higher education institutions (Pryimakov, Dotsenko, 2006; Novytskyi, 2010; Seluyanov, Dimova, 2002; Samokysh, 2018), most of them fail to take into account the ratio and interrelations of different preparation system constituents. In particular, the importance of coordination preparation for increasing motor skills of students, reserve capabilities of their motor system, including those necessary to enhance functional capacities and the level of development of motor qualities, are not sufficiently accounted for.

The analysis of indices of student physical and technical fitness during the experiment (100 m and 3,000 m running, standing long jumps, shuttle running, expert estimate of the quality of executing hip-rolls, leg trips and sweeps and the duration of performing their separate phases) allowed to reveal certain interrelations between motions of various coordination structure and to formulate more accurately general notions about the level of their development and functioning of the system of motion control under different conditions.

Positive associations were noted between the results in shuttle running and long jump, on the one hand, and those in $100 \mathrm{~m}$ and $3,000 \mathrm{~m}$ running - on the other.

These dependencies may be interpreted in such a way that the improvement of the quality of coordination changes in standing long jump and shuttle run occurs in parallel with the improvement of the result in short and long distance running. That is, there is a certain interdependence of the level of development of individual motor qualities and coordination of movements both in the process of ontogenetic development, and in the process of special physical preparation (aimed at the development of speed, endurance, speed-strength qualities and a number of coordination abilities).

The results allow to assume that the enhancement of specialized motions of various coordination structure in the process of Alish belt wrestling not only improves the phase temporal structure of these motions (duration of separate phases of throw execution is reduced along with the improvement of the motor control quality according to the results of expert estimate) but also contributes to the improvement of results in non-specialized motions with different character of energy supply and various structure of movements, which details and supplements the findings of other authors.

Statistically significant positive associations between the result in sprint running (100 m and 3,000 m) and the data of shuttle run, standing long jumps and pull-ups indicate an availability of positive crossed transfer between speed and general endurance, speed and strength endurance, speed and agility.

Short distance running represents a fast and coordination-wise complex movement. Time of the run-up, high speed at the distance are provided not only by the morphological structure of the motor system, the power and capacity of the corresponding energy sources (phosphagens), the activity of enzymes, but also by the coordination changes in the motion control system - improvement of intramuscular and intermuscular coordination, that of nervous processes and sensory systems. Intermuscular coordination is based on the mechanisms of reciprocal innervation of leg antagonist muscles, has an innate character, but is improved in the process of long-term adaptation to physical loads (Pryimakov, Monogarov, 2000).

Based on the above, it can be affirmed that there exists an interrelation of several major indices of speed, speed-strength and coordination capacities of the EG students: 
- increased speed of $100 \mathrm{~m}$ running is associated with improved speed-strength capacities (standing long jumps), coordination abilities (shuttle run), general endurance (3,000 m run),

- improved coordination in shuttle run is associated with increased speed-strength (results in standing long jump) and speed (100 m run) capacities, general (3,000 m run) and strength endurance (pull-ups),

- improved result in speed-strength and complex coordinated test - standing long jump is associated with increased strength (pull-ups), dynamic (sit-ups in $1 \mathrm{~min}$ ) and general endurance (3,000 m run), as well as improved coordination reorganizations of agility (shuttle run) and speed (100 m run).

Regular engagement in Alish belt wrestling leads to significant improvement of physical and functional state indices:

- strength of the right and the left hand increases (by $33.5 \%$ and $30.2 \%$, respectively),

- duration of hip-rolls and the initial phases of action reduces, whereas the quality of motor control tends to improve (according to expert estimate),

- vital index increases by $34.3 \%$, VC - by $42.4 \%$, endurance - by $20.3 \%$, speed - by $12.9 \%$, agility - by $21.8 \%$, speed-strength capacities - by $12.7 \%$,

- time of recovery after physical loads reduces and the indices of physical work capacity and circulation efficiency show significant improvement.

Therefore, generalization of the above-analyzed material allows to conclude that among the indices that determine physical fitness of the EG students, those which reflect their motor capacities in strength data, indices of agility, speed-strength tests and spine flexibility tend to prevail unlike indices of the CG students.

These differences may be explained by more qualitative rearrangements in the motor system of the EG students that occurred both in the process of their ontogenetic development, and under the influence of Alish belt wrestling, thus indicating higher functional reserves of their motor system, including coordination capacities.

Comprehensiveness of wrestlers' motor preparation, founded on the principles of a systematic approach in pedagogics, is the basis and criterion for studying the functional reserves of student motor system.

The findings supplement the results of studies of a number of authors, who dealt with the problem of functional reserves of student motor system (Pryimakov, Dotsenko, 2006; Pryimakov, Dotsenko, Prysyazhnyuk, 2014; Samokysh, 2016; Samokish, Bosenko, Pryimakov, Biletskaya, 2017).

\section{Conclusions}

Variety of student motor activity while practicing Alish belt wrestling during non-school hours and the performance of skills of different coordination structures contribute to development of various, including special, motor capacities of wrestlers, reduce the duration of realization of separate phases of executed motions, increase the quality of their performance and extend students' motor reserve capacities.

The improvement of specialized motions of different coordination structures while practicing Alish belt wrestling contributes to enhancement of the results in both specialized and non-specialized movements with different character of energy supply and different motion structure, improves functional state indices, reduces the time of recovery after physical loads and increases the level of general work capacity. 


\section{References}

Apanasenko, G.L. (2004). Health protection of healthy: some issues of theory and practice. Valeology: diagnostics, tools and health practices. Saint Petersburg: Science.

Arefyev, V.G. (2010). Bases of theory and methods of physical education. Kiev: National Pedagogical University of the name M.P. Drahomanov.

Arziutov, H.M., Hrishchenkov, V.N., Chizhaiev, P. (2009). Search for bright formula of fight in Alish belt wrestling by means of improving FILA competition rules. Bulletin of Chernigov State Pedagogical University named after T.G. Shevchenko. Producing 64. Series: Pedagogical sciences. P.E and sport. Chernihiv: CSPU, 64, 233-237.

Blume, D.D. (1983). Der sportmotorische Test als Forschungsmethoden. Theorie und Praxis der Körperkultur, 6, $446-448$.

Blume, D.D. (1984). Einige aktuelle Probleme des Diagnostizierens koordinativer Fähigkeiten mit sportmotorischen Tests. Theorie und Praxis der Körperkultur, 2, 122-124.

Hirtz, P., Vilkner, H.J. (1985). Nutzung der Geratetechnik zur Erhohung der Aussagefähigkeit sportmotorischer Tests in der sportmetodischen Forschung. Theorie und Praxis der Körperkultur, 9, 682-686.

Jascaninas, I., Monogarov, V. (1987). Peripheral compensation mechanisms of muscle fatigue. Svecatos Apsauge, 12, 27-29.

Krutsevych, T.I. (2012). Theory and methods of physical education, Vol. 2. Kiev: Olympic Literature.

Mekota, K., Blahus, P. (1983). Motoricke testy v telesne vychove. Prague: SPN.

Novytskyi, I.V. (2010). Comparative characteristics of student morphofunctional state during 1981-2009 period. Scientific journal of the State Pedagogical University named after Mikhail Drahomanov: collection of scientific works. Producing, 7, 204-207.

Pryimakov, A.A. (2011). Activity of muscles and intermuscular interrelations while managing cyclic repeated motions under conditions of athlete strenuous muscular activity. Scientific Journal of the SPU Named after Mikhail Drahomanov. Series 15, Producing 11, NPU of the Name M.P, 211-215.

Pryimakov, A.A., Dotsenko, E.N. (2006). Problems of physical education at higher education institutions as a factor of health strengthening and enhancing motor capacities of students. Pedagogics, Psychology, Medicalbiological Problems of Physical Training and Sports, 5, 83-88.

Pryimakov, A.A., Monogarov, V.D. (2000). Activity of muscles and intermuscular interrelations in athletes during managing program motions under conditions of strenuous muscular activity. Science is in Olympic Sport, Special Producing, 47-55.

Pryimakov, O.O., Dotsenko, O.M., Prysiazhniuk, S.I. (2014). Improvement of reserve capacities of the system of managing motions of different coordination structure in female students of special medical group. Scientific Journal of the SPU Named after Mikhail Drahomanov. Series 15, Producing ZK 14 (44), NPU of the Name M.P., 457-461.

Pryimakov, O.O., Dovhych, O.O. (2003). Improvement of sensory system functions in the process of teaching students of motions of different coordination structure. Scientific Messages of the Kiev Mohyla Academy, 2 (22), 324-226.

Samokish, I., Bosenko, A., Pryimakov, O., Biletskaya, V. (2017). Monitoring system of functional ability of university students in the process physical education. European Journal of Sport Sciences and Medicine, 17 (1), 75-80.

Samokysh, I.I. (2016). Physical work capacity as a basis of student youth functional capacities. Physical Education of Students, 6 , 40-48.

Samokysh, I.I. (2018). Monitoring functional capacities of students of higher educational institutions in the process of physical education. Odessa: ONAZ to the name O.C. Попова.

Schnabel, G. (1994). Bewegungsregulation als Informationsorganisation. Trainingswissenschaft. Berlin: Sportverlag.

Seluyanov, V.N., Dimova, A.L. (2002). Control of student physical fitness by means of low load tests. VI International Scientific Congress the Olympic Sport and Sport for All. Warsaw, 6-9 June, 46 (1, 2), 287-288.

Sergienko, L.P. (2001). Complex testing of human motor capacities. Mykolaiv: UDMTU.

State Program of physical culture and sport development in Ukraine: approved by the Order of President of Ukraine on June 22, 1994 N 334 (1994), Kiev.

Cite this article aS: Voloshin, O., Kolenkov, O. (2019). Improvement of Student Physical State and Coordination of Movements by Means of Alish Belt Wrestling. Central European Journal of Sport Sciences and Medicine, 2 (26), 47-56. DOI: 10.18276/ cej.2019.2-05. 